\title{
Assessment of bone age by cervical vertebral dimensions in lateral cephalometric radiographs
}

\author{
Bashir Ahmad Wani ${ }^{1, *}$, Altaf Hussain Chalkoo ${ }^{2}$, Saima Tariq ${ }^{3}$, Aslam Bedar ${ }^{4}$ \\ ${ }^{1,3,4} \mathrm{PG}$ Student, ${ }^{2}$ Professor and HOD, ${ }^{1,2,3}$ Dept. of Oral Medicine and Radiology, ${ }^{4}$ Dept. of Orthodontics and Dentofacial \\ Orthopaedics, Government Dental College Srinagar, Jammu and Kashmir, India
}

*Corresponding Author: Bashir Ahmad Wani

Email: drbashir.omar7@gmail.com

\begin{abstract}
Aim and Objectives: For determining the skeletal/bone age from hand-wrist radiographs, Greulich and Pyle's Atlas and TannerWhitehouse 3 (TW3) methods are considered as reliable methods, but there are concerns of extra radiation dose. The cervical vertebral bone age (CVBA) by measurements of the vertebral body of third $\left(\mathrm{C}_{3}\right)$ and fourth $\left(\mathrm{C}_{4}\right)$ is a relatively new method of objectively evaluating the skeletal maturation. The aim of this study was to estimate bone age by measuring 3rd and 4th cervical vertebral $\left(\mathrm{C}_{3}, \mathrm{C}_{4}\right)$ dimensions.

Materials and Methods: Lateral cephalometric and hand-wrist radiographs of 40 male and 46 female subjects (08-16 years of age) who had attended Government Dental College Srinagar for treatment were taken and measurements of C3 and C4 was done by using NNT Dicom version 7.0.0.0 software. Hand-wrist bone age was determined using Pyle and Greulich Atlas. Stepwise multiple regression analysis demonstrated the correlation between the measurements.

Results: Anterior height of the third cervical vertebrae $\left(\mathrm{AH}_{3}\right)$ in males had the strongest correlation with hand-wrist bone age $(\mathrm{r}=1.0, \mathrm{p}<0.01)$. Standard error for the coefficient of $\mathrm{AH}_{3}$ was 10.733. The highest correlation coefficient in females was observed between $\mathrm{H}_{3}$ and the estimated bone age from Greulich's Atlas ( $\left.\mathrm{r}=0.896, \mathrm{p}<0.05\right)$. Standard error for the coefficient of $\mathrm{H}_{3}$ was 10.43 . The bone age was calculated by multiple regression model: Bone age in males $=0.809 \times \mathrm{AH}_{3}+2.896$. Adjusted $\mathrm{R} 2$ was $0.153(\mathrm{p}<0.01)$ and in females $=0.370 \times \mathrm{H}_{3}+2.752$. Adjusted $\mathrm{R} 2$ was $0.245(\mathrm{p}<0.05)$.

Conclusions: Lateral cephalometric radiographs might be an alternative to the hand-wrist radiography for bone age estimation. Therefore, analysis of cervical vertebrae by replacing hand-wrist method additional radiograph could be avoided.
\end{abstract}

Keywords: Cervical vertebral bone age, Lateral cephalometric radiographs, Hand-wrist radiographs.

\section{Introduction}

Skeletal maturation is evaluated to indicate the level of body maturation as well as the remaining growth potential in children as chronological age is not the accurate measure of growth status and overall physical maturation. ${ }^{1}$ Researchers have used many parameters for a reliable indicator of maturity and/or growth potential such as chronological age, secondary sexual characteristics, body weight and height, menarche or voice changes, dental development, skeletal development and vertebral development. ${ }^{2}$ Assessment of the degree of ossification of certain bony markers located within the skeletal system can be used for Skeletal maturation. The phalanges and metacarpal bones are most commonly a convenient method of estimating the skeletal maturity level through handwrist radiographs. ${ }^{3}$ For determining the skeletal/bone age from hand-wrist radiographs, Greulich and Pyle atlas ${ }^{[4]}$ and Tanner-Whitehouse 3 (TW3) methods ${ }^{5}$ are considered as reliable, but there are concerns of extra radiation dose. The British Orthodontic Society guidelines have stated that there is no indications of the hand and wrist radiographs for predicting the onset of pubertal growth spurt. ${ }^{6}$

The cervical vertebral bone age (CVBA) by measurements of the vertebral body of third $\left(\mathrm{C}_{3}\right)$ and fourth $\left(\mathrm{C}_{4}\right)$ is a relatively new method of objectively evaluating the skeletal maturation. ${ }^{7}$ Lamparski in 1972, had published an atlas that shows changes of cervical vertebral bodies in evaluating skeletal maturations. ${ }^{8}$ Hellsing had found a significant correlation between dimensions of the cervical vertebral bodies and statural height during adulthood. ${ }^{9}$ Hassel and Farman in 1995 suggested six stages for cervical vertebral maturation and had found a high correlation between cervical vertebral body maturation and hand-wrist, but stage differentiation was difficult because of subjective method, and quantitative evaluation of growth is not possible. $^{10}$

The purpose of this retrospective study was to estimate bone age by measuring the dimensions of the cervical vertebral bodies of $\mathrm{C}_{3}$ and $\mathrm{C}_{4}$ on Lateral cephalometric radiographs and to investigate its correlation with hand-wrist bone age using Greulich and Pyle atlas in Kashmiri population.

\section{Materials and Methods}

The sample comprises of standardized lateral cephalometric and hand-wrist radiographs of 40 male and 46 female subjects (08-16 years of age) who had attended Government Dental College Srinagar for treatment. Inclusion criteria include subjects free of any serious illness, no previous trauma or injury to the head and neck region, and no form of previous orthodontic treatments. All lateral cephalometric and hand-wrist radiographs were taken by New-Tom VGi Scanner (QR srl; Verona, Italy) in standard resolution mode and analyzed them by NNT Dicom version 7.0.0.0 software. 
All cephalometric radiographs were measured by a single experienced examiner and the following measurements were performed on the vertebral body of $\mathrm{C}_{3}$ and $\mathrm{C}_{4}$; anterior vertebral body height (AH), vertebral body height $(\mathrm{H})$, posterior vertebral body height $(\mathrm{PH})$, and antero-posterior vertebral body length (AP), as shown in Fig. 1.

The chronological age and the ratios of the measured parameters were analysed in order to derive a statistical model to determine the CVBA through a stepwise multiple regression analysis. By using the well-established methods of Greulich and Pyle atlas, the hand-wrist radiographs were used to determine the skeletal/bone age of the subjects. The data was tabulated and analyzed using Student's t-test, descriptive analysis, and Pearson's correlation coefficient in SPSS for Windows version 16.80 (SPSS Inc., Chicago, IL, USA).

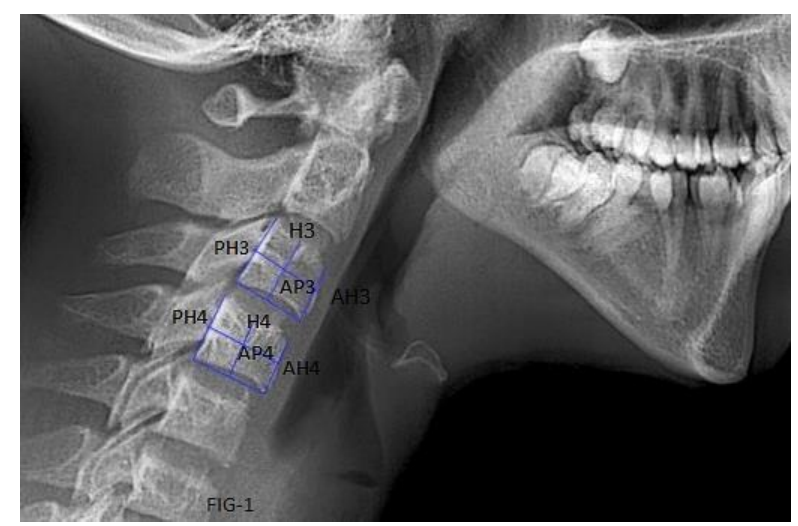

\section{Results}

The sample included 46 females $(53.48 \%)$ and 40 males $(46.51 \%)$ respectively. The mean bone age in males was 12.8 years $(\mathrm{SD}=1.47)$ with age in the range of 9 to 15 year and in females was 11.98 years $(\mathrm{SD}=2.188)$ with age in the range of 8 to 16 years. Anterior height of the third cervical vertebrae $\left(\mathrm{AH}_{3}\right)$ in males had the strongest correlation with hand-wrist bone age $(\mathrm{r}=1.0, \mathrm{p}<0.01)$ as shown in table-1 and 2 . Standard error for the coefficient of $\mathrm{AH}_{3}$ was 10.733 . The bone age was calculated by multiple regression model: Bone age in males $=0.809 \times \mathrm{AH}_{3}+2.896$. Adjusted R2 was $0.153(\mathrm{p}<0.01)$

\section{Fig. 1}

Table 1: The statistics of each variable in males

\begin{tabular}{|l|c|c|c|c|c|c|c|c|c|}
\hline & Bone age & $\mathbf{A H}_{\mathbf{3}}$ & $\mathbf{P H}_{\mathbf{3}}$ & $\mathbf{H}_{\mathbf{3}}$ & $\mathbf{A P} \mathbf{3}$ & $\mathbf{A H _ { 4 }}$ & $\mathbf{P H}_{\mathbf{4}}$ & $\mathbf{H}_{\mathbf{4}}$ & $\mathbf{A P}_{\mathbf{4}}$ \\
\hline Mean & 12.8 & 8.86 & 12.21 & 10.38 & 13.28 & 8.63 & 12.15 & 9.95 & 13.43 \\
\hline S.D & 1.47 & 1.70 & 1.69 & 1.81 & 1.27 & 1.66 & 1.59 & 1.63 & 1.31 \\
\hline Minimum & 9 & 6 & 9 & 8 & 11 & 6 & 10 & 8 & 11 \\
\hline Maximum & 15 & 13 & 15 & 14 & 16 & 12 & 16 & 13 & 16 \\
\hline
\end{tabular}

Table 2: Pearson's correlation coefficient of each variable in Males

\begin{tabular}{|c|c|c|c|c|c|c|c|c|}
\hline & $\mathrm{AH}_{3}$ & $\mathrm{PH}_{3}$ & $\mathrm{H}_{3}$ & $\mathrm{AP}_{3}$ & $\mathrm{AH}_{4}$ & $\mathrm{PH}_{4}$ & $\mathrm{H}_{4}$ & $\mathrm{AP}_{4}$ \\
\hline Pearson's r & 1.0 & 0.809 & 0.915 & 0.451 & 0.914 & 0.757 & 0.906 & 0.554 \\
\hline
\end{tabular}

The highest correlation coefficient in females was observed between $\mathrm{H}_{3}$ and the estimated bone age from Greulich's Atlas $(r=0.896, p<0.05)$ as shown in table 3 and 4. Standard error for the coefficient of $\mathrm{H}_{3}$ was 10.43 . Bone age in females $=0.370 \times \mathrm{H}_{3}+2.752$. Adjusted R2 was $0.245(\mathrm{p}<0.05)$.

Table 3: The statistics of each variable in females

\begin{tabular}{|l|c|c|c|c|c|c|c|c|c|}
\hline & Bone age & $\mathbf{A H}_{\mathbf{3}}$ & $\mathbf{P H}_{\mathbf{3}}$ & $\mathbf{H}_{\mathbf{3}}$ & $\mathbf{A P}$ & $\mathbf{A H}_{\mathbf{4}}$ & $\mathbf{P H}_{\mathbf{4}}$ & $\mathbf{H}_{\mathbf{4}}$ & $\mathbf{A P}_{\mathbf{4}}$ \\
\hline Mean & 11.98 & 9.13 & 12.25 & 10.43 & 12.51 & 8.87 & 12.21 & 10.17 & 12.34 \\
\hline S.D & 2.188 & 1.751 & 1.560 & 1.659 & 1.379 & 1.797 & 1.456 & 1.727 & 1.345 \\
\hline Minimum & 8 & 6 & 10 & 8 & 10 & 6 & 10 & 8 & 10 \\
\hline Maximum & 16 & 12 & 15 & 14 & 14 & 12 & 15 & 14 & 14 \\
\hline
\end{tabular}


Table 4: Pearson's correlation coefficient of each variable in females

\begin{tabular}{|c|c|c|c|c|c|c|c|c|}
\hline & $\mathbf{A H}_{\mathbf{3}}$ & $\mathbf{P H}_{\mathbf{3}}$ & $\mathbf{H}_{\mathbf{3}}$ & $\mathbf{A P}_{\mathbf{3}}$ & $\mathbf{A H}_{\mathbf{4}}$ & $\mathbf{P H}_{\mathbf{4}}$ & $\mathbf{H}_{\mathbf{4}}$ & $\mathbf{A P}_{\mathbf{4}}$ \\
\hline Pearson's r & 0.860 & 0.789 & 0.896 & 0.219 & 0.886 & 0.866 & 0.876 & 0.066 \\
\hline
\end{tabular}

\section{Discussion}

Development of the child depends on individual's differences in the magnitude of growth with different individuals requiring different time factor to achieve maturity. Hence it is important for the clinician to identify the maturation level of an individual to make a suitable decision on the timing of the treatment options. ${ }^{13}$ Assessment of the degree of skeletal maturation by Hand wrist radiographs or cervical vertebral maturation on lateral cephalograms has shown to be effective method for quantification of growth. ${ }^{12}$ The most common and convenient method of estimating the skeletal maturity level is through phalanges and metacarpal bones of hand-wrist radiographs. ${ }^{3}$ For determining the skeletal/bone age from hand-wrist radiographs, Greulich and Pyle atlas ${ }^{4}$ and Tanner-Whitehouse 3 (TW3) methods ${ }^{5}$ are considered as reliable methods, but have concerns of extra radiation dose. The British Orthodontic Society guidelines have stated that there is no indications of the hand and wrist radiographs for predicting the onset of pubertal growth spurt. ${ }^{6}$ The assessment of cervical vertebral bone age (CVBA) by measurements of the vertebral body of third $\left(\mathrm{C}_{3}\right)$ and fourth $\left(\mathrm{C}_{4}\right)$ is a relatively new method of objectively evaluating the skeletal maturation. ${ }^{7}$ The main reason for rising popularity of cervical vertebral bone age on lateral cephalograms is because of its regularly used film in orthodontic diagnosis. ${ }^{13}$ Lamparski evaluated growth of cervical vertebrae in a subjective manner with morphological characteristics such as concavity of the lower border, and height and shape of the vertebral bodies. ${ }^{14}$ In 1995 Hassel and Farman had suggested six stages for cervical vertebral maturation with high correlation between cervical vertebral body maturation and hand-wrist maturation, but, because of subjective method, stage differentiation was difficult and quantitative evaluation of growth not possible. In 2005, Baccetti et al. had introduced a modified version of the Cervical Vertebral Maturation (CVM) method, considered now as the most widely accepted method. ${ }^{15}$

In this study we estimated bone age by measuring the dimensions of the cervical vertebral bodies of $\mathrm{C}_{3}$ and $\mathrm{C}_{4}$ on Lateral cephalometric radiographs and to investigate its correlation with hand-wrist bone age using Greulich and Pyle atlas. We found highest correlation coefficient between $\left(\mathrm{AH}_{3}\right)$ and hand-wrist bone age $(\mathrm{r}=1.0, \mathrm{p}<0.01)$ in males as shown in table 1 and 2, between $\mathrm{H}_{3}$ and the estimated bone age from Greulich's Atlas $(\mathrm{r}=0.896, \mathrm{p}<0.05)$ in females as shown in table 3 and 4. Masoud Varshosaz et al had reported highest correlation coefficient between $\mathrm{AH}_{4}$ and the estimated bone age from Greulich's Atlas $(\mathrm{r}=0.831$, $\mathrm{p}<0.001){ }^{16}$
Chang et al. ${ }^{17}$ and Lai et $\mathrm{al}^{18}$ had reported a strong correlation between CVM and Hand wrist model for boys $(r=0.97 / 0.91)$ and girls $(r=0.97 / 0.94)$. Caldas Mde et al. found significant correlation between CVM and bone age and used (AH3/AP3, AH4/AP4) ratios in females and (AH3/AP3 and H4/AP4) in males to calculate the CVBA in multiple regression analysis. ${ }^{19}$ Mito et al. found that there was significantly $(\mathrm{P}<0.05)$ higher correlation coefficient between CVBA and bone age by the TW2 method $(r=0.869)$ than that between cervical vertebral bone age and chronological age $(\mathrm{r}=0.705)$. However, only Japanese girls were studied by them. ${ }^{7}$ Therefore, Lateral cephalometric radiographs might be an alternative to the hand-wrist radiography for bone age estimation.

\section{Conclusions}

Lateral cephalometric radiographs might be an alternative to the hand-wrist radiography for bone age estimation. In this study, the results indicate that the CVBA assessment by the described statistical analysis is as dependable in determining the skeletal maturation as the other well-established hand-wrist methods of Greulich and Pyle atlas. Therefore, analysis of cervical vertebrae by replacing hand-wrist method, additional radiographs could be avoided.

\section{References}

1. Hagg U, Taranger J. Maturation indicators and the pubertal growth spurt. Am J Orthod. 1982;82:299-309.

2. Baccetti T, Franchi L, McNamara Jr JA. The Cervical Vertebral Maturation(CVM) method for the assessment of optimal treatment timing in dentofacial orthopedics. Semin Orthod. 2005;11(3):119-29.

3. Fishman LS. Radiographic evaluation of skeletal maturation. A clinically oriented method based on handwrist films. Angle Orthod. 1982;52:88-112.

4. Greulich WW, Pyle SI. Radiographic atlas of skeletal development of hand and wrist. 2nd ed. Stanford: Stanford University Press; 1959.

5. Tanner JM, Whitehouse RH, Cameron N, Marshall WA, Healy MJR, Goldstein NH. Assessment of skeletal maturity and prediction of adult height(TW3 method). 3rd ed. London: WB Saunders; 2001.

6. Turpin DL. British Orthodontic Society revises guidelines for clinical radiography. Am J Orthod Dento-facial Orthop. 2008;134(5):597-8.

7. Mito T, Sato K, Mitani H. Cervical vertebral bone age in girls. Am J Orthod Dentofacial Orthop. 2002;122:380-5.

8. Lamparski D. Skeletal age assessment utilizing cervical vertebrae [Unpublished master's thesis]. Pittsburgh: University of Pittsburgh 1972.

9. Hellsing E. Cervical vertebral dimensions in 8-, 11-, and 15-year-old children. Acta Odontol Scand. 1991;49(4):207-13.

10. Hassel B, Farman AG. Skeletal maturation evaluation using cervical vertebrae. Am J Orthod Dento-facial Orthop. 1995;107:58-66. 
11. Kucukkeles N, Acar A, Biren S, Arun T. Comparisons between cervical vertebrae and hand-wrist maturation for the assessment of skeletal maturity. J Clin Pediatr Dent. 1999;24:47-52.

12. Bacceti T, Franchi L, McNamara Jr. JA. The cervical vertebrae maturation (CVM) method for the assessment of optimal treatment timing in dentofacial orthopedics. Semin Orthod. 2005;11:119-129.

13. Baccetti T, Franchi L, McNamara JA Jr. An improved version of the cervical vertebral maturation (CVM) method for the assessment of mandibular growth. Angle Orthod. 2002;72:316-23.

14. Lamparski DG. Skeletal age assessment utilizing cervical vertebrae [master's thesis]. Pittsburgh (PA): University of Pittsburgh; 1972.

15. Proffit W, Fields H, Sarver D. Treatment of skeletal problems in children. In: Proffit WR FH, Sarver D, ed. Contemporary orthodontics. St Louis: Mosby 2007:497.
16. Masoud Varshosaz. Bone age estimation by cervical vertebral dimensions in lateral cephalometry, progress in orthodontics 2012;13:126-131.

17. Chang HP, Liao CH, Yang YH, Chang HF, Chen KC. Correlation of cervical vertebral maturation with handwrist maturation in children. Kaohsiung J Med Sci. 2001;17:29-35.

18. Lai EHH, Liu JP, Chang JZC. Radiographic assessment of skeletal maturation stages for orthodontic patients: hand-wrist bones or cervical vertebrae? J Formos Med Assoc. 2008;107:316-325.

19. Caldas Mde P, Ambrosano GM, Haiter Neto F. New formula to objectively evaluate skeletal maturation using Lateral cephalometric radiographs. Braz Oral Res. 2007;21:330-5. 